\title{
A REBELIÃO URBANA NA SOCIEDADE MODERNA
}

\author{
URBAN REBELLION IN MODERN SOCIETY
}

Gabriel Franco da Rosa Lopes*

\begin{abstract}
Resumo:
O presente artigo pretende descrever a emergência de rebeliões urbanas na sociedade moderna, servindo-se para isso de uma analise fundada, de um lado na teoria dos campos de Pierre Bourdieu; de outro, na teoria dos sistemas de Niklas Luhmann, sem a sobreposição, permitindo que atuem complementarmente. Concomitantemente, serão mobilizadas as as pesquisas de Stéphane Beaud e Michel Pialoux e os eventos ocorridos na França em 2005.
\end{abstract}

Palavras-chave: Rebeliões urbanas. Teoria dos sistemas. Teoria dos campos. Pierre Bourdieu. Niklas Luhmann.

\begin{abstract}
:
This paper aims to describe the rise of urban rebellions in modern society, using for its purposes an analysis based on the fields theory of Pierre Bourdieu and the systems theory of Niklas Luhmann, without any superposition, allowing that both theories act supplementary. Simultaneously, it will be mobilized the researches of Stéphane Beaud and Michel Pialoux and the events occurred in France in 2005.
\end{abstract}

Keywords: Urban rebellions. Systems theory. Fields theory. Pierre Bourdieu. Niklas Luhmann.

\section{Introdução}

A morte de dois jovens no subúrbio de Paris “que, perseguidos pela polícia quando voltavam de um jogo de futebol, se refugiaram em uma central elétrica, onde morreram eletrocutados", ${ }_{1}^{1}$ deu início a uma série de manifestações, que culminaram na

Mestrando em Filosofia e Teoria Geral do Direito pela Faculdade de Direito da Universidade de São Paulo. Graduado em Direito pela Universidade Presbiteriana Mackenzie.

1 A produção deste artigo para a disciplina de Movimentos Sociais e Acesso à Justiça, matéria ministrada pelo Professor Celso Fernandes Campilongo, no Programa de Pós-Graduação da Faculdade de Direito da Universidade de São Paulo, deve muito às aulas, às leituras e aos debates promovidos durante o curso. O cerne das comparações entre as teorias de Niklas Luhmann e Pierre Bourdieu apresenta-se como uma primeira exposição das pesquisas desenvolvidas na dissertação de mestrado em curso, que pretende estabelecer convergências e divergências entre as sociologias jurídicas entre os autores mencionados, sob a orientação do Professor Orlando Villas Bôas Filho. Por este motivo, cabe alertar ao leitor do caráter provisório dos resultados e de incompletudes que possam ser percebidas no desenvolvimento dos argumentos.

BEAUD, S.; PIALOUX, M. Rebeliões urbanas e a desestruturação das classes populares (França, 2005). Tradução de Vera Telles e revisão técnica de Sérgio Miceli. Revista Tempo Social: Revista de Sociologia da USP, São Paulo, v. 18, n. 1, p. 37, . 
decretação do famigerado estado de sítio, ${ }^{2}$ em uma violenta ação por parte do Estado, ${ }^{3}$ deflagrando um conflito social que permanecia latente. Em que pese a perplexidade de alguns analistas desavisados frente ao aumento brutal dos veículos incendiados ${ }^{4}$ e a proliferação de atos ostensivos, atribuídos pelo então presidente da Nicolas Sarkozy a "arruaceiros" ou "delinquentes", tal fato de modo algum trazia surpresa aos sociólogos Stéphane Beaud e Michel Pialoux, que não por acaso, dois anos antes já haviam diagnosticado a possibilidade da ocorrência de eventos como estes na obra Violences Urbaines, violence sociale, ${ }^{5}$ continuação das pesquisas iniciadas em Retour sur la condition ouvrière. Estes autores, colaboradores de Pierre Bourdieu na obra La misère du monde, haviam avançado seus estudos no fenômeno ocorrido nos anos 90 com a mudança do modo de produção ${ }^{6} \mathrm{e}$ na organização dos grupos sociais, cujos reflexos atingiram não apenas a economia, mas também a educação, a estrutura familiar e o modo de vida destes operários, ${ }^{7}$ os quais, tiveram sua condição de "classe mobilizada" gradualmente deteriorada à de uma "classe objeto", 9 ou como bem denominam Beaud e Pialoux: à condição de "operários após a classe operária". ${ }^{10}$

Partindo do cenário apontado pelos autores de Retour sur la condition ouvrière, ${ }^{11}$ especialmente em Rebeliões urbanas e a desestruturação das classes

2 ARANTES, Paulo E. Alarme de incêndio no gueto francês: uma introdução à era da emergência. Discursos Sediciosos, Rio de Janeiro, v. 17/18, p. 205-260, 2011.

3 Id., Ibid.

4 Id., Ibid.

5 Cf. BEAUD, S.; PIALOUX, M. Rebeliões urbanas e a desestruturação das classes populares (França, 2005). Tradução de Vera Telles e revisão técnica de Sérgio Miceli. Revista Tempo Social: Revista de Sociologia da USP, São Paulo, v. 18, n. 1, p. 37-59 e ARANTES, Paulo E. Alarme de incêndio no gueto francês: uma introdução à era da emergência. Discursos Sediciosos, Rio de Janeiro, v. 17/18, p. 205-260, 2011.

6 Estas mudanças ocorridas são apontadas como a adoção do modo de produção japonês em substituição ao taylorismo e as diversas formas de desmobilização promovidas ao longo da década de 90. BEAUD, S.; PIALOUX, M. Retour sur la condition ouvrière. Paris: Fayard, 1999. p. 29-157 (em português BEAUD, S.; PIALOUX, M. Retorno à condição operária. São Paulo, Boitempo Editorial, 2009. p. 21-110).

7 Para uma reconstrução completa, Cf. BEAUD, S.; PIALOUX, M. Violences urbaines, violence sociale. Paris: Fayard, 2003; BEAUD, S.; PIALOUX, M. Retour sur la condition ouvrière. Paris: Fayard, 1999 (também disponível em português BEAUD, S.; PIALOUX, M. Retorno à condição operária. São Paulo: Boitempo Editorial, 2009).

8 Cf. BOURDIEU, P. A distinção: crítica social do julgamento. Tradução de Daniela Kern e Guilherme J.F. Teixeira. 2. ed., revisada. Porto Alegre: RS: Zouk, 2011. p. 514, nota de rodapé 6.

9 BOURDIEU, P. Une classe objet. In: Actes de la recherché en sciences sociales. v. 17-18, novembro de 1977, p. 5.

10 PIALOUX, M. Retour sur la condition ouvrière. Paris: Fayard, 1999. p. 417-427 (na tradução brasileira BEAUD, S.; PIALOUX, M. Retorno à condição operária. São Paulo: Boitempo Editorial, 2009. p. 293300).

11 Neste caso nos socorreremos às pesquisas desenvolvidas por Beaud e Pialoux, para suprir a ausência de estudos empíricos, respeitando, por conseguinte os limites impostos por este tipo de abordagem, principalmente no tocante ao alcance deste aparato para a explicação de fenômenos que venham a ocorrer. Em suma, trataremos de uma construção hipotética e eminentemente teórica, contudo, não completamente apartada de constatações empíricas, a fim de elucidar a possibilidade de ocorrência de novos eventos, 
populares (França, 2005), o presente artigo pretende demonstrar como a emergência de protestos deste tipo - classificados, ao final, como rebeliões urbanas - decorre de características intrínsecas à sociedade moderna, servindo-se, para isso, do instrumental teórico desenvolvido pela teoria dos sistemas de Niklas Luhmann, centrado principalmente na obra $A$ sociedade da sociedade, ${ }^{12}$ em um diálogo com a teoria dos campos de Pierre Bourdieu $^{13}$ e de seus discípulos Beaud e Pialoux. Aproximação esta, bastante profícua como acentua Pfeilstetter, ${ }^{14}$ que nos permitirá superar o dualismo entre teorias da sociedade como grupos de pessoas e teorias da sociedade como esferas de função e seus mecanismos institucionais, conforme classificação de Lockwood apresentada por Pokol. ${ }^{15}$

\section{A sociedade funcionalmente diferenciada}

Partiremos de uma premissa dada pela teoria dos sistemas, a diferenciação da sociedade em subsistemas de função, esferas não hierarquizadas, organizadas em torno de um código binário de valoração e de um meio, surgida, aproximadamente, na segunda metade do século XVIII, na Europa. ${ }^{16}$ A formação social a que nos referimos é o resultado de um processo histórico, imbricado aquilo que a tradição marxista denomina Capitalismo, ${ }^{17}$ na qual o fechamento operacional de subsistemas funcionais constituídos por comunicação - ou seja, que produzem e reproduzem a si próprios autopoieticamente

semelhantes aos descritos.

12 A escolha da obra $A$ sociedade da sociedade não é, de modo algum, arbitrária. A fundamentação para a realização deste corte decorre do fato desta obra conter a versão final e mais bem acabada da teoria dos sistemas.

13 Cf. PFEILSTETTER, R. Bourdieu y Luhmann. Diferencias, similitudes, sinergias. Revista Internacional de Sociología, v. 70, n. 3, p. 506-507, set./dez. 2012; que enfatiza a possibilidade de operar conjuntamente a teoria dos sistemas e dos campos, propiciando um aumento bastante razoável do potencial explicativo, fato este que pode ser extraído também de POKOL, B. 2002. "Contribution to the comparison of the theories of Bourdieu and Luhmann.”, Jogelméleti Szemle 3. Disponível em: < http://jesz.ajk.elte.hu/pokol112.html>. Acesso em: 14 jun.2013, e aplicado ao caso do direito em VAN KRIEKEN, R. "Legal reasoning as a field of knowledge production: Luhmann, Bourdieu, and law's autonomy." Paper presented at the annual meeting of the The Law and Society Association, de 27 a 30 de Maio, Chicago, U.S.A. Disponível em: <http://prijipati. library.usyd.edu.au/bitstream/2123/967/1/legal\%20reasoning.pdf $>$. Acesso em: 25 jun. 2013.

14 PFEILSTETTER, R. Bourdieu y Luhmann. Diferencias, similitudes, sinergias. Revista internacional de Sociología, v. 70, n. 3, p. 506-507, set./dez., 2012.

15 POKOL, B. 2002. "Contribution to the comparison of the theories of Bourdieu and Luhmann.", Jogelméleti Szemle 3. Disponível em: <http://jesz.ajk.elte.hu/pokol112.html>. Acesso em: 14 jun. 2013.

16 Cf. LUHMANN, Niklas. La sociedad de la sociedad, p. 589 e ss. Cabe uma atenção especial à reconstrução da caracterização da sociedade moderna feita em VILLAS BÔAS FILHO, Orlando. Teoria dos sistemas e o direito brasileiro, 2009; visto que a partir de diversas análises é verificada a possibilidade da utilização da teoria dos sistemas no direito brasileiro.

17 Tal aproximação entre o capitalismo e a diferenciação funcional, aqui apontada, encontra-se exaustivamente desenvolvida em BACHUR, J. P. Às portas do labirinto: para uma recepção crítica da teoria social de Niklas Luhmann, p. 139-156. 
- permitiria a estes uma abertura cognitiva de uns ao outros, através de relações bilaterais assimétricas, evolutivamente obtidas, os acoplamentos estruturais. ${ }^{18}$

Não nos guiaremos, inicialmente, pelo modelo de Bourdieu, visto sua despreocupação com as funções sociais dos campos, ${ }^{19}$ a qual ocasiona, inclusive, problemas na delimitação da modernidade, ${ }^{20}$ como aponta Martuccelli. A passagem para a teoria de Bourdieu, realizada a seguir, trará à luz alguns aspectos ausentes na teoria dos sistemas, capazes de aprofundar nossa abordagem do fenômeno em comento.

\section{A desigualdade social na sociedade funcionalmente diferenciada}

Como é possível notar sem grandes esforços, a diferenciação funcional, não elimina completamente os estratos sociais, característicos de uma forma de diferenciação funcional anterior. ${ }^{21}$ Estes permanecem existindo, ainda que de forma não representativa à sociedade, constituindo o que Luhmann denomina, em última análise, desigualdade social. ${ }^{22}$ Permanece a diferença entre ricos e pobres, principalmente no que tange ao modo de vida, tal como demonstra P. Bourdieu em $A$ distinção.

Interessante notar, que Luhmann lança mão, no trecho em comento, de um conceito de processo, ${ }^{23}$ a fim de convencer da insustentabilidade desta cisão social frente à

18 BACHUR, J. P. Às portas do labirinto: para uma recepção crítica da teoria social de Niklas Luhmann, p. 156-172.

19 Vejamos, inclusive, o que POKOL, B. 2002. "contribution to the comparison of the theories of Bourdieu and Luhmann." Jogelméleti Szemle 3. Disponível em: <http://jesz.ajk.elte.hu/pokol112.html>. Acesso em: 03 abr. 2010, remetendo a um texto ainda não disponível em português, BOURDIEU, P. La noblesse $d$ 'État. Grandes écoles et esprit de corps. Paris: Minuit, p. 376, nota que apenas em uma nota de rodapé Bourdieu revela que a diferenciação dos campos remeteria a Durkheim e Spencer, o que decorreria segundo o comentador da disputa política que existia no meio acadêmico francês, a qual, por comporse predominantemente de uma esquerda-libertária, não aceitaria remissões a teóricos classificados como conservadores, como é o caso de Parsons. Ao contrário, Bourdieu, a todo o tempo, parece reforçar as divergências entre sua teoria e a de Talcott Parsons (por exemplo, cf. BOURDIEU, P. "Introdução a uma sociologia reflexiva". In: O poder simbólico. Tradução de Fernando Tomaz. 16. ed. Rio de Janeiro: Bertrand Brasil, 2012, p. 17-58; ou mesmo, cf. BOURDIEU, Pierre. "!Viva la crisis! Por la heterodoxia em las ciencias sociales". In: Poder, derecho y classes sociales, p. 63-86).

20 MARTUCCELLI, D. Sociologies de la modernité. p. 140-141.

21 Não nos cabe aqui desenvolver a passagem da sociedade estratificada para a sociedade funcionalmente diferenciada, posto que nossa análise incidirá diametralmente sobre a última. Cabe notar que Bachur de modo bastante esclarecedor diferencia dois tipos de estratificação: aquela por camadas sociais da diferenciação e uma outra como modo de diferenciação social. A distinção é bastante útil para a captação do fenômeno sem o equívoco de pensar em uma manutenção da sociedade estratificada, tornando evidente o modo como a primeira delas se manteve após a alteração da segunda. BACHUR, J. P. Às portas do labirinto. p. 225). Denominaremos, doravante, a primeira destas, como Luhmann o faz, de estratificação residual. Para uma reconstrução bastante didática das formas de diferenciação que precederam a sociedade funcionalmente diferenciada, cf. VILLAS BÔAS FILHO, Orlando. Teoria dos sistemas e o direito brasileiro. São Paulo: Saraiva, 2009. p. 101-104.

22 LUHMANN, Niklas. La sociedad de la sociedad, p. 612-613.

23 Os processos são uma sequência de acontecimentos comunicativos irreversíveis, observáreis por conta 
diferenciação funcional, mantida, como destaca o referido autor, pelo acaso. ${ }^{24}$ A reprodução destas diferenças de oportunidades de vida, não mais vinculadas à diferenciação social, encontra-se atrelada, segundo Luhmann, a uma seletividade perversa, produto secundário da racionalidade operativa dos sistemas funcionais, principalmente o econômico e o educacional, reforçando o desvio. ${ }^{25}$

Poderíamos avançar um pouco mais com Bachur e criticar frontalmente tal ideia subjacente de acaso, tomando tal estratificação como característica típica da Sociedade Moderna, conforme trata Bourdieu à revelia de Luhmann, ${ }^{26}$ contudo nos interessa aprofundar antes uma diferença fundamental entre os dois últimos autores.

Aquilo que pretendemos enfatizar é o aspecto que a contingência ocupa na teoria Luhmann. A improbabilidade é um signo que orienta a teoria dos sistemas A radical contingência do mundo se acentua no fato da unidade analítica deste autor ser a comunicação, não mais o sujeito. ${ }^{27}$ Bourdieu, por outro lado, dirige sua teoria a analise de determinantes do comportamento prático, fato este bem delineado na celebre frase " $O$ mundo social não é uma roleta". ${ }^{28}$

Não se pode pensar, contudo, que as teorias em debate são em absoluto antagônicas, visto que Luhmann apresenta um conceito de estrutura, apto a descrever uma sociedade caracterizada por constantes mudanças, também com meios de comunicação simbolicamente generalizados os quais agiriam de modo a aumentar o êxito na compreensão da comunicação, promovendo uma diminuição neste terceiro momento da operação. Bourdieu, por outro lado, com seu uso reiterado de estatísticas, demonstra não o descarte de todas as possibilidades em face de uma necessidade, mas que nem todas as probabilidades são igualmente possíveis. Nesta linha, tal como aponta Pfeilstetter, devemos notar que o conceito de habitus e a importância dada por Luhmann à socialização, buscam de maneiras distintas, explicar como se dá a intermediação entre as instituições sociais e as dimensões física e psíquica dos indivíduos. ${ }^{29}$ Podemos observar, deste modo,

destruturas duráveis, como aponta CORSI, G. ESPOSITO, Elena \& BARALDI, C. Glosario sobre la teoría social de Niklas Luhmann, p. 131. A noção de "processo", presente no trecho "Pero aun dentro de la estratificación que ya no es estamentaria el proceso continúa, sobre todo en la desaparición de las capas superiores urbanas - conocidas en la ciudad." (grifamos) (LUHMANN, Niklas. La sociedad de la sociedad, p. 612), em uma interpretação sistemática da obra $A$ sociedade da sociedade, deve ser lida não como um fato que virá a ocorrer necessariamente, mas uma probabilidade decorrente das estruturas sociais.

24 LUHMANN, N. "Zur Begriff der sozialen klasse", p. 144/145 Apud: BACHUR, J.P. Às portas do labirinto. p. 225.

25 LUHMANN, Niklas. La sociedad de la sociedad. p. 614 nota de rodapé 332.

26 Idem, ibidem.

27 LUHMANN, Niklas. La sociedad de la sociedad, 2006.

28 BOURDIEU, Pierre. Las formas del capital. Capital económico, capital cultural y capital social. In: Poder, derecho y classes sociales. p. 131 a 164.

29 PFEILSTETTER, R. Bourdieu y Luhmann. Diferencias, similitudes, sinergias. Revista Internacional de Sociología, v. 70, n. 3, p. 500-501, set./dez. 2012. 
que, ainda que os autores pendam a lados distintos, um para a "determinação" e outro para a "liberdade", ${ }^{30}$ as teorias dão conta de ambos os pontos.

Assim, voltando ao percurso de Bachur, corroborado pelas pesquisas Pierre Bourdieu, resta patente a necessidade de crítica à explicação (ou ausência dela) de que a estratificação residual provenha meramente do acaso. ${ }^{31}$ Até porque, como demonstra o autor de Às portas do labirinto seria um contrassenso admitir que a inclusão e a exclusão se transferem entre os diversos sistemas, e que a estratificação permanece adstrita a um subsistema social. ${ }^{32}$ A prática, como comprova Bourdieu em suas pesquisas empíricas, demonstra o contrário, aproximando-se mais de uma sobredeterminação que de uma indeterminação. ${ }^{33}$

Neste sentido cabe enfatizar com Bachur e Bourdieu, ${ }^{34}$ o papel das famílias e do sistema de ensino na aquisição do capital cultural e econômico (ainda que Luhmann renegue tal ponto da obra do autor francês, ${ }^{35}$ ao que tudo indica, em decorrência da garantia do primado da observação da sociedade em seu funcionamento global), ${ }^{36}$ a fim de entendermos estas heranças sociais, as quais nos levariam a constatação feita pelo autor de Às portas do labirinto, a radical formulação de que a diferenciação funcional engendra estratificação, segmentação e regionalização, padrões não funcionais de diferenciação, cujo resultado é a negação desta sociedade nela própria em seu funcionamento. ${ }^{37}$ Ainda com este autor, é possível notar que a ausência do conceito de classe na teoria luhmanniana, prejudica a observação de como famílias, regiões e camadas sociais condicionam a

30 Vale frisar que mencionamos aqui, tendências, com o intuito exclusivo de distinguir as teorias, visto que tentar apresentar distanciamentos maiores que estes, nesta temática, poder resultar em uma apresentação caricatural das teorias.

31 BACHUR, J. P. Às portas do labirinto, p. 225-229.

32 Id. Ibid.

33 Cf. BOURDIEU, P. A distinção: crítica social do julgamento. cit., p. 101.

34 Muitas das convergências entre estes dois autores, são, mais propriamente, as convergências entre Marx e Bourdieu. O próprio Bourdieu desenvolveu em alguns textos certas semelhanças e diferenças entre o seu trabalho e o de Marx (cf. BOURDIEU, P. Introdução a uma sociologia reflexiva. In: O pode simbólico. Tradução de Fernando Tomaz. 16 ed. Rio de Janeiro: Bertrand Brasil, 2012. p. 17-58 e BOURDIEU, P. Espaço social e gênese das 'classes'. In: $O$ pode simbólico. Tradução de Fernando Tomaz. 16 ed., Rio de Janeiro: Bertrand Brasil, 2012,p. 133-159). Cabe destacar igualmente, a publicação das aulas de Burawoy, realizada através da organização de Ruy Braga, que exploram de modo bastante detido estas interações (BURAWOY, M. O marxismo encontra Bourdieu. Organizador: Ruy Gomes Braga Neto; tradução, referências bibliográficas e notas: Fernando Rogério Jardim. Campinas: Editora Unicamp, 2010).

35 LUHMANN, N. La sociedad de la sociedad. Tradução para o espanhol de Javier Torres Nafarrate. Cidade do México: Editorial Herder, 2006. p. 465.

36 Deste modo como bem destaca POKOL, B. 2002. "contribution to the comparison of the theories of Bourdieu and Luhmann.” Jogelméleti Szemle 3. Disponível em: <http://jesz.ajk.elte.hu/pokol112.html>. Acesso em: 03 abr. 2010.

37 O argumento de Bachur, exposto de modo bem sucinto, perpassa toda a construção do capítulo Contradições da sociedade funcionalmente diferenciada. (BACHUR, J.P. Às portas do labirinto. cit., p. 197-254). 
reprodução da sociedade, ${ }^{38}$ o que, parece ser justificável a luz da dicotomia apontada por Lockwood.

Bourdieu utiliza dois conceitos de classe: a construída e a mobilizada. ${ }^{39}$

O conceito de classe construida apontado por Bourdieu refere-se a constante luta social de grupos pela acumulação de bens simbólicos, bem como pela legitimação dos critérios de classificação. Trata-se de uma construção analítica e não propriamente de uma realidade dada, visto ser esta o espaço de relações multidimensional do mundo social. ${ }^{40}$

A classe mobilizada, à qual será dada uma maior atenção, do mesmo modo que o realizado por Pialoux e Beaud em seus estudos, decorre de uma agregação de agentes baseada em propriedades comuns, ou seja, a partir da proximidade das posições entre os agentes nesta luta de classes e classificações. ${ }^{41}$

Abordaremos, com isso, os conflitos sociais, a fim de observarmos como a erosão desta última classe, descrita pela teoria dos campos, e a fragmentação dos conflitos pelo procedimento, descrita pela teoria dos sistemas, foram fenômenos sincrônicos que permitiram o surgimento de protestos como os franceses, classificados a seguir, como rebeliões urbanas.

\section{A gênese dos conflitos sociais}

Descrito o fenômeno de estratificação típico da sociedade moderna, resta demonstrar como os conflitos sociais são gerados.

Os conflitos aparecem na teoria de Niklas Luhmann, como sistemas parasitários, perigosos para a reprodução autopoietica sociedade por colocarem em risco as operações. ${ }^{42}$ Estes decorrem da contradição e não-aceitação de expectativas, ${ }^{43}$ "condensando instabilidade social", conforme explica Campilongo. ${ }^{44} \mathrm{O}$ procedimento surge neste contexto como sistema capaz de manter decidir conflitos e com isso, manter a sociedade estabilizada, ${ }^{45}$ ou seja, um conflito permitido, como trata Luhmann.

38 BACHUR, J.P. Às portas do labirinto. cit., p. 239.

39 Não se pode perder de vista que o conceito de classe em Bourdieu não é aquele apresentado por Marx, por exemplo no O Capital (Cf. FAUSTO, Ruy. Sobre as classes. In: Marx: lógica e política. São Paulo: Editora Brasiliense, 1987. p. 201-286); cabendo notar inclusive certas características próprias da tradição marxiana francesa de autores como Kojève e Hippolyte, tal como aponta ORTIZ, R. A porosidade da fronteira das Ciências Sociais. In: A sociologia de Pierre Bourdieu. cit., p. 19.

40 BOURDIEU, P. Espaço social e gênese das ‘classes'. In: O pode simbólico, p. 137.

41 Cf. BOURDIEU, P. A distinção: crítica social do julgamento. cit., p. 514, nota de rodapé 6 e cf. BOURDIEU, P. Une classe objet. In: Actes de la recherché en sciences sociales. v. 17-18, novembro de 1977, p. 5.

42 BACHUR, J. P. Às portas do labirinto. cit., p. 243.

43 BACHUR, J. P. Às portas do labirinto. cit., p. 243.

44 CAMPILONGO, C. F. Interpretação do direito e movimentos sociais. cit., p. 85.

45 LUHMANN, N. Legitimação pelo procedimento. cit., p. 39-40. 
Em um plano como o de Luhmann, no qual a diferenciação funcional parece solapar o caráter imediato entre estratificação e conflito, ${ }^{46}$ observaremos o surgimento destes conflitos urbanos - mais adiante, especificados como rebeliões - como resíduos não imunizáveis pelo procedimento, ou mesmo, fragmentos de revolta decorrentes da ação imunizante do procedimento.

O procedimento apresenta-se, na teoria dos sistemas, como um sistema imunizador, capaz de garantir a alteração de estruturas da sociedade, preservando a reprodução operativa da sociedade funcionalmente diferenciada, por meio da institucionalização de conflitos. ${ }^{47}$ Estes impedem, conforme bem explicita Bachur: " $a$ frustração se condense em uma instituição social capaz de orientar simbolicamente a ação", ${ }^{48}$ remetendo a revolta de volta ao ambiente. ${ }^{49}$

No plano dos grupos sociais, ou classes, Bourdieu observa a existência constante de lutas na sociedade, no interior de campos, em decorrência da divisão desigual dos capitais. Com isso, a estabilização ocorre também de modo dinâmico, por conta das estratégias para a ocupação de posição superiores, bem como pela illusio, ${ }^{50}$ o nãoreconhecimento dos agentes da arbitrariedade dos símbolos, fazendo-os jogar seriamente, aceitando as regras, tal como incorpora o autor francês as ideias de jogos de linguagem de Wittgenstein. ${ }^{51}$

$46 \quad$ BACHUR, J.P. Às portas do labirinto. cit., p. 239.

47 A reconstrução da obra Legitimação pelo procedimento, à luz, da fase "autopoética" de Luhmann (para seguirmos a classificação de Guibentif, cf. GUIBENTIF, P. O direito na obra de Niklas Luhmann. Etapas de uma evolução teórica. In: O pensamento de Niklas Luhmann, p. 185-252) aqui presente, foi norteada pelos três textos de Bachur (BACHUR, J. P. Conflito, procedimento e novos movimentos sociais - uma perspectiva a partir da teoria de sistemas de Niklas Luhmann, $6^{\circ}$ encontro da ABPC, Campinas, 2008, BACHUR, J.P. Distanciamento e crítica: limites e possibilidades da teoria de sistemas de Niklas Luhmann. Tese de Doutorado apresentada ao Departamento de Ciência Política da Faculdade de Letras, Ciências Humanas e Filosofia da USP e BACHUR, J.P. Às portas do labirinto, 2010) os quais tratam o tema de modo muito mais detido. Contudo, não prosseguiremos em sua análise acerca dos protestos como sistemas de imunização, por conta inclusive, destes protestos específicos aqui abordados, de serem conflitos não permitidos (para utilizarmos uma analogia com Luhmann) cujos atos de destruição patrimonial serviram inclusive, no caso da França, para a decretação do Estado de Sítio. Nossa análise, destarte, não invalida a de Bachur, neste ponto, visto que a possibilidade de destes protestos serem imunizadores pode existir em outros casos.

48 BACHUR, J.P. Às portas do labirinto. cit., p. 248.

49 Idem, ibidem.

50 Cf. BOURDIEU, P. Meditações pascalianas. cit., p. 123-124.

51 Cf. BOURDIEU, P. Coisas ditas , p. 21. A apropriação dos jogos de linguagem das Investigações Filosóficas de Wittgenstein, não se trata de uma incorporação direta, mas principalmente do uso de explicações, como a do "jogo de xadrez" (Cf. WITGENSTEIN, L. Investigações filosóficas. In: Os Pensadores. cit., p. 31) e a "arbitrariedade das regras da gramática" (Cf. WITGENSTEIN, L. Investigações filosóficas. In: $O s$ Pensadores. p. 186), a fim de compreender os motivos pelos quais obedecemos as regras. Assim, é possível, por exemplo, visualizar o jogar seriamente mencionado por Bourdieu (Cf. BOURDIEU, P. Meditações Pascalianas. p. 22-23), tal prática coincide com o exemplo muito ilustrativo de que o "mundo social não é um jogo de sorte”" (cf. BOURDIEU, P. Meditações Pascalianas, p. 262), provocados pela interiorização do 
Em ambas as teorias, como se percebe, a sociedade lida com os conflitos e lutas sem grandes dificuldades, através de mecanismos de manutenção social próprios, fato este, que sofrerá um deslocamento ao tratarmos da rebelião urbana, visto não se tratar de um conflito permitido, conforme será desenvolvido.

\section{A rebelião urbana}

Alcançamos aqui o tema a que versa o presente, artigo: a rebelião urbana. Tal classificação, inexistente na obra luhmanniana, advém dos trabalhos de Pialoux e Beaud Violences urbaines, violence sociale e Rebeliões urbanas e a desestruturação das classes populares (França, 2005). ${ }^{52}$ Tais ocorrências são sintomas, como se poderia constatar, de um amplo fenômeno de erosão dos mecanismos protetivos das denominadas classes populares, resultantes de uma alteração no modo de produção fabril e na organização social, como demonstra o texto diversas vezes mencionado, Retour sur la condition ouvrière. A este contexto de fragilização, decorrente da perda de representatividade dos sindicatos ou de partidos que permitiram a proteção destas classes, combinadas com uma opressão, promovida principalmente pela perseguição étnica, constrói-se o que Beaud e Pialoux denominam "classe perigosa". ${ }^{53}$

$\mathrm{O}$ enquadramento das rebeliões urbanas à teoria dos sistemas se dará pelo que Luhmann denomina protesto, ${ }^{54}$ visto ser um tipo de sistema, intermediário às interações e às organizações. ${ }^{55}$ Contudo, algumas especificidades destes deverão ser cuidadosamente tratadas, a fim de permitir à teoria dos sistemas apreender eventos como aqueles ocorridos em França no ano de 2005.

Assim, as rebeliões urbanas se organizam em torno da forma protesto, compostas, de um lado por aqueles que protestam e de outro os que demonstram reprovar

habitus como sistema de disposições.

52 A tradução do termo émeute aqui utilizada, seguiu à de Vera Telles (cf. BEAUD, S.; PIALOUX, M. Rebeliões urbanas e a desestruturação das classes populares (França, 2005). Tradução de Vera Telles e revisão técnica de Sérgio Miceli. Revista Tempo Social: Revista de sociologia da USP, São Paulo: v. 18, n. 1), tendo em vista a adequação do termo ao tipo de interação social a que pretendemos apontar na teoria dos sistemas de Niklas Luhmann.

53 BEAUD, S.; PIALOUX, M. Violences urbaines, violence sociale. p. 404 e ss.

54 O tema dos movimentos de protesto, ainda que desenvolvido de modo bastante esparso por Luhmann, encontra-se reconstruído de modo bastante cuidadoso em (CAMPILONGO, C. F. Interpretação do direito e movimentos sociais. Rio de Janeiro: Elsevier, 2012). Contudo, para as finalidades a que se pretende o presente artigo, tomaremos a questão do protesto frente ao fenômeno empírico descrito, realizando os ajustes necessários, adotando o modo como estes são tratados na obra $A$ sociedade da sociedade, como referência.

55 Vale notar que o protesto, aparece na obra $A$ sociedade da sociedade, como um intermediário entre os sistemas de interação e as organizações, com características comuns a cada um. (cf. LUHMANN, Niklas. La sociedad de la sociedad. cit., p. 674-675.) 
tais ações, restando um lugar privilegiado no exterior da forma à polícia. ${ }^{56}$ Não apenas por este fator, contudo, a polícia localiza-se como o "adversário por excelência" destes "conflitos". Tal como se pode notar o estopim destes atos, uma perseguição policial que terminou com a morte de dois jovens na França, foi capaz de deflagrar de uma só vez o preconceito $^{57}$ (no caso contra o estrangeiro) e a banalização do excesso, ${ }^{58}$ que pautava o uso da violência legítima, ${ }^{59}$ utilizando a terminologia weberiana, coroados pela decretação do Estado do Sítio.

Se distanciando do modelo exposto por Luhmann, as rebeliões urbanas não possuem temas, ou seja, elas podem ser vistas como fins em si mesmos. Neste sentido, enquanto um movimento de protesto poderia terminar tanto pela desmotivação como pelo alcançar do objetivo pleiteado, as rebeliões urbanas, pela ausência de temas e, consequentemente, da tensão entre tema e protesto, podem ser encerradas pela desmotivação ou pela repressão. O movimento em cadeia, provocado pela ausência de um objetivo, todavia, dificulta a estabilização social, até porque, é a própria estabilidade dinâmica da sociedade funcionalmente diferenciada uma das causas para a emergência destes, conforme se pretende demonstrar.

As rebeliões urbanas, assim como os protestos, são, também, frutos da fragmentação dos conflitos em revoltas promovida pelo procedimento e, por este mesmo motivo não possuem qualquer potencial revolucionário ou reformista, ${ }^{60}$ enquanto tais. ${ }^{61}$

56 Não apenas este motivo é a causa da relação bastante áspera entre a polícia e a população que vive na periferia das grandes cidades como uma vasta bibliografia de estudos empíricos de Loïc Wacquant deixa claro (cf. WACQUANT, L. Os condenados da cidade: estudos sobre marginalidade avançada. Tradução de João Roberto Martins Filho. 2. ed. Rio de Janeiro: Revan, 2005 e WACQUANT, L. Punir os pobres: a nova gestão da miséria nos Estados Unidos. Rio de Janeiro: F. Bastos, 2001. Revan 2003).

57 Este tema é exaustivamente desenvolvido em BEAUD, S.; PIALOUX, M. Rebeliões urbanas e a desestruturação das classes populares (França, 2005). Tradução de Vera Telles e revisão técnica de Sérgio Miceli. Revista Tempo Social: Revista de Sociologia da USP, São Paulo, v. 18, n. 1, p. $37-59$ e BEAUD, S.; PIALOUX, M. Violences urbaines, violence sociale. Paris: Fayard, 2003.

58 ARANTES, Paulo E. Alarme de incêndio no gueto francês: uma Introdução à Era da Emergência. Discursos Sediciosos, Rio de Janeiro, v. 17/18, p. 205-260, 2011.

59 E, porque não dizer violência simbólica legítima também, se observarmos a adesão do operariado Francês a bandeiras de ódio aos estrangeiros.

${ }^{60}$ Assim como apontado por Bachur quanto às diferenças entre os movimentos de protesto e o modelo clássico de política socialista (cf. BACHUR, João Paulo. Distanciamento e crítica: limites e possibilidades da teoria de sistemas de Niklas Luhmann. Tese (Doutorado) - Departamento de Ciência Política da Faculdade de Letras, Ciências Humanas e Filosofia, Universidade de São Paulo), podemos destacar que a ausência de uma meta "capaz de orientar teleologicamente a luta política e social".

${ }_{61}$ O que de modo algum impede que um movimento social ou partido político capte tal movimentação em seu favor. Basta ver para isso, como a Frente Nacional, um partido conservador francês, obteve adesão do eleitorado operário, graças a hostilidade deste para com os estrangeiros, que causavam à época medo de desemprego PIALOUX, M. Retour sur la condition ouvrière, p. 375-415 (na tradução brasileira BEAUD, S.; PIALOUX, M. Retorno à condição operária. cit., p. 265-292). 
O uso de ambas as teorias justifica-se neste momento, visto que a emergência destas não nos parece em absoluto evidente à luz de uma análise pautada exclusivamente na teoria dos sistemas, contudo, esta teoria nos garante a observação da organização social, captando mecanismos de estabilização social ausentes nas teorias dos campos.

Ao final do presente artigo, muito ainda permanece intocado no que concerne às rebeliões urbanas, visto que, tal como advertido no início, o ponto de partida eleito, as pesquisas de Beaud e Pialoux, trouxeram ao lume apenas alguns dos aspectos necessários para uma compreensão da relação entre este fenômeno e a sociedade moderna. Para esta finalidade a teoria dos sistemas de Niklas Luhmann parece ter mais a nos dizer. O tema, como se mostrou, ainda está longe de ser exaurido, por conta dos muitos problemas ainda a serem enfrentados, principalmente no que concerne a sociedade global e as questões referentes à economia, ou sistema econômico. Assim, restam suscintamente iniciados aqui, alguns questionamentos sobre este tema, que nos parece bastante relevador para a compreensão da sociedade moderna.

\section{Conclusão}

A partir dos trabalhos desenvolvidos por Stéphane Beaud e Michel Pialoux, foi possível observar que a teoria dos campos poderia fornecer explicações bastante relevantes para a compreensão das rebeliões urbanas, ocorridas em França no ano de 2005. Para a superação das limitações do instrumental teórico utilizado por tais autores, originalmente elaborado por Pierre Bourdieu, na observação daquilo que caracteriza a sociedade moderna, bem como das funções de seus campos, servimo-nos da teoria dos sistemas de Niklas Luhmann. A partir de leituras de Luhmann e Bourdieu e graças à contribuição de Bachur, captamos o fenômeno da estratificação residual. Com isso, pudemos compreender a gênese dos conflitos sociais, e a imunização da sociedade promovida pelo procedimento. Neste contexto, a emergência das rebeliões urbanas é explicada a luz da teoria dos sistemas e dos campos, trazendo cada uma, a seu modo, contribuições para a apreensão do fenômeno.

São Paulo, junho de 2013.

\section{Referências}

ARANTES, Paulo E. Alarme de incêndio no gueto francês: uma introdução à era da emergência. Discursos Sediciosos, Rio de Janeiro, v. 17/18, p. 205-260, 2011.

BACHUR, J. P. Às portas do labirinto. São Paulo: Azougue Editorial, 2010. 
. Conflito, procedimento e novos movimentos sociais: uma perspectiva a partir da teoria de sistemas de Niklas Luhmann, $6^{\circ}$ encontro da ABPC. Campinas, 2008.

. Distanciamento e crítica: limites e possibilidades da teoria de sistemas de Niklas Luhmann. Tese (Doutorado) - Departamento de Ciência Política da Faculdade de Letras, Ciências Humanas e Filosofia, Universidade de São Paulo, São Paulo.

BEAUD, S.; PIALOUX, M. Rebeliões urbanas e a desestruturação das classes populares (França, 2005). Tradução de Vera Telles e revisão técnica de Sergio Miceli. Revista Tempo Social: Revista de Sociologia da USP, v. 18, n. 1, p. 37-59, jun. 2006.

. Retorno à condição operária. São Paulo: Boitempo Editorial, 2009.

. Retour sur la condition ouvrière. Paris: Fayard, 1999.

. Violences urbaines, violence sociale. Paris: Fayard, 2003.

BOURDIEU, P. A distinção: crítica social do julgamento. Tradução de Daniela Kern e Guilherme J.F. Teixeira. 2. ed. revisada. Porto Alegre: Zouk, 2011.

. A sociologia de Pierre Bourdieu. São Paulo: Editora Olho d’água, 2003.

. Coisas ditas. Tradução de Cássia R. da Silveira e Denise Moreno Pegorim. 1. ed. São Paulo: Brasiliense, 1990.

. Espaço social e gênese das 'classes'. In: O pode simbólico. Tradução de Fernando Tomaz. 16. ed. Rio de Janeiro: Bertrand Brasil, 2012. p. 133-159.

. Introdução a uma sociologia reflexiva. In: O poder simbólico. Tradução de Fernando Tomaz. 16. ed. Rio de Janeiro: Bertrand Brasil, 2012. p. 17-58.

. Las formas del capital. Capital económico, capital cultural y capital social. In: Poder, derecho y classes sociales. p. 131-164.

. Meditações pascalianas. Tradução de Sérgio Miceli. Rio de Janeiro: Bertrand Brasil, 2001. . Une classe objet. In: Actes de la recherché en sciences sociales. v. 17-18, novembro de 1977.

- ¡Viva la crisis! Por la heterodoxia em las ciencias sociales. In: Poder, derecho y classes sociales. p. 63-86.

BURAWOY, M. O marxismo encontra Bourdieu. Organizador: Ruy Gomes Braga Neto; tradução, referências bibliográficas e notas: Fernando Rogério Jardim, Campinas, SP: Editora Unicamp, 2010.

CAMPILONGO, C. F. Interpretação do direito e movimentos sociais. Rio de Janeiro: Elsevier, 2012.

CORSI, G. ESPOSITO, Elena; BARALDI, C. Glosario sobre la teoría social de Niklas Luhmann. Tradução de M. R. Pérez e C. Villalobos. Barcelona: Anthropos, 1996. 
FAUSTO, Ruy. Sobre as classes. In: Marx: Lógica e Política. São Paulo: Editora Brasiliense, 1987. p. 201-286.

GUIBENTIF, P. O direito na obra de Niklas Luhmann. Etapas de uma evolução teórica. In: COVILHÃ, José Manuel dos Santos (Org.). O pensamento de Niklas Luhmann. Portugal: Universidade Beira Interior, 2005.

LUHMANN, N. Legitimação pelo procedimento. Tradução de Maria da Conceição Côrte-Real. Brasília: Editora Universidade de Brasília, 1980.

. La sociedad de la sociedad. Tradução para o espanhol de Javier Torres Nafarrate. Cidade do México: Editorial Herder, 2006.

MARTUCCELLI, Danilo. Sociolgies de la modernité. Paris: Gallimard, 1999.

ORTIZ, R. A porosidade da fronteira das ciências sociais. In: A sociologia de Pierre Bourdieu. São Paulo: Editora Olho d'água, 2003.

PFEILSTETTER, R. Bourdieu y Luhmann. Diferencias, similitudes, sinergias. Revista Internacional de Sociología, v. 70, n. 3, set./dez. 2012.

POKOL, B. Contribution to the comparison of the theories of Bourdieu and Luhmann. Jogelméleti Szemle 3. 2002. Disponível em: <http://jesz.ajk.elte.hu/pokol112.html>. Acesso em: 14 jun. 2013.

VAN KRIEKEN, R. Legal reasoning as a field of knowledge production: Luhmann, Bourdieu, and law's autonomy. Paper presented at the annual meeting of the The Law and Society Association, de 27 a 30 de Maio, Chicago, U.S.A. Disponível em: <http://prijipati.library.usyd.edu.au/ bitstream/2123/967/1/legal\%20reasoning.pdf >. Acesso em: 25 jun. 2013.

VILLAS BÔAS FILHO, Orlando. Teoria dos sistemas e o direito brasileiro. São Paulo: Saraiva, 2009.

WACQUANT, L. Os condenados da cidade: estudos sobre marginalidade avançada. Tradução de João Roberto Martins Filho. 2. ed. Rio de Janeiro: Revan, 2005.

WACQUANT, L. Punir os pobres: a nova gestão da miséria nos Estados Unidos. Tradução de Eliana Aguiar, Rio de Janeiro: F. Bastos, 2001. Revan, 2003.

WITTGENSTEIN, L. Investigações filosóficas. In: Os Pensadores. São Paulo: Nova Cultural, 1999. 